\title{
vvECMO can be avoided by a transpulmonary pressure guided open lung concept in patients with severe ARDS
}

\author{
Philip van der Zee ${ }^{*} \mathbb{D}$, Dinis Dos Reis Miranda, Han Meeder, Henrik Endeman and Diederik Gommers
}

\section{Dear Editor,}

The EOLIA trial concluded that vvECMO compared to conventional mechanical ventilation with low tidal volumes and airway pressures $\leq 30 \mathrm{cmH}_{2} \mathrm{O}$ did not improve survival [1]. Although not statistically significant, the $11 \%$ absolute reduction in mortality rate and multiple crossovers to rescue vvECMO were considered to be clinically relevant [2]. However, a conventional mechanical ventilation strategy is likely to be insufficient for patients with severe ARDS, as higher airway pressures are required to maintain lung aeration [3]. Grasso et al. measured the transpulmonary pressure $\left(\mathrm{P}_{\mathrm{L}}\right)$ in patients with severe ARDS and increased PEEP until $\mathrm{P}_{\mathrm{L}}$ was 25 $\mathrm{cmH}_{2} \mathrm{O}$. Fifty percent of patients responded to an increase in airway pressure and did not require vvECMO [4]. We hypothesized that a $\mathrm{P}_{\mathrm{L}}$ guided open lung concept (OLC) could improve oxygenation and prevent conversion to vvECMO in patients with severe ARDS.

We retrospectively reviewed the records of all patients referred to our ICU between January and May 2018. Eight patients had severe ARDS and had an indication for vvECMO according to the EOLIA trial (demographics are given in the Additional file 1) [1]. Before referral protective mechanical ventilation with low tidal volume and a plateau pressure of approximately $30 \mathrm{cmH}_{2} \mathrm{O}$ was applied. $\mathrm{PaO}_{2} / \mathrm{FiO}_{2}$ ratio was $62 \pm 7 \mathrm{mmHg}$ despite the use of neuromuscular blocking agents and prone positioning. After referral, a recruitment maneuver was performed and PEEP was increased. $\mathrm{P}_{\mathrm{L}}$ was estimated with an esophageal balloon catheter and we aimed for a $\mathrm{P}_{\mathrm{L}} \leq 25$ $\mathrm{cmH}_{2} \mathrm{O}$. In addition, respiratory rate and I:E ratio were increased, thereby generating intrinsic PEEP.

The $\mathrm{P}_{\mathrm{L}}$ guided OLC resulted in an increase in $\mathrm{PaO}_{2} /$ $\mathrm{FiO}_{2}$ ratio to $201 \pm 87 \mathrm{mmHg}$ (Fig. 1) and none of the patients required vvECMO. During the first $6 \mathrm{~h}$ peak airway pressure was increased to $44.9 \pm 10.2 \mathrm{cmH}_{2} \mathrm{O}$, but was reduced to $36.3 \pm 5.6 \mathrm{cmH}_{2} \mathrm{O}$ within $24 \mathrm{~h}$, while PEEP was maintained at $20.6 \pm 4.0 \mathrm{cmH}_{2} \mathrm{O}$. A maximum end-inspiratory $\mathrm{P}_{\mathrm{L}}$ of $18 \pm 5 \mathrm{cmH}_{2} \mathrm{O}$ was measured. At $72 \mathrm{~h}$ both peak airway pressures and PEEP were reduced to baseline values while oxygenation remained stable.

These data suggest that the OLC improves oxygenation and avoids conversion to vvECMO in patients with severe ARDS. We acknowledge that a recruitment maneuver and higher PEEP in patients with moderate to severe ARDS increased mortality in the Alveolar Recruitment Trial [5]. However, the recruitment maneuver was standardized and

* Correspondence: p.vanderzee@erasmusmc.nl

A part of this data will be presented in poster format at ISICEM 2019.

Department of Adult Intensive Care, Erasmus MC, Doctor Molewaterplein 40,

3015, GD, Rotterdam, the Netherlands

(C) The Author(s). 2019 Open Access This article is distributed under the terms of the Creative Commons Attribution 4.0 International License (http://creativecommons.org/licenses/by/4.0/), which permits unrestricted use, distribution, and

reproduction in any medium, provided you give appropriate credit to the original author(s) and the source, provide a link to the Creative Commons license, and indicate if changes were made. The Creative Commons Public Domain Dedication waiver (http://creativecommons.org/publicdomain/zero/1.0/) applies to the data made available in this article, unless otherwise stated. 

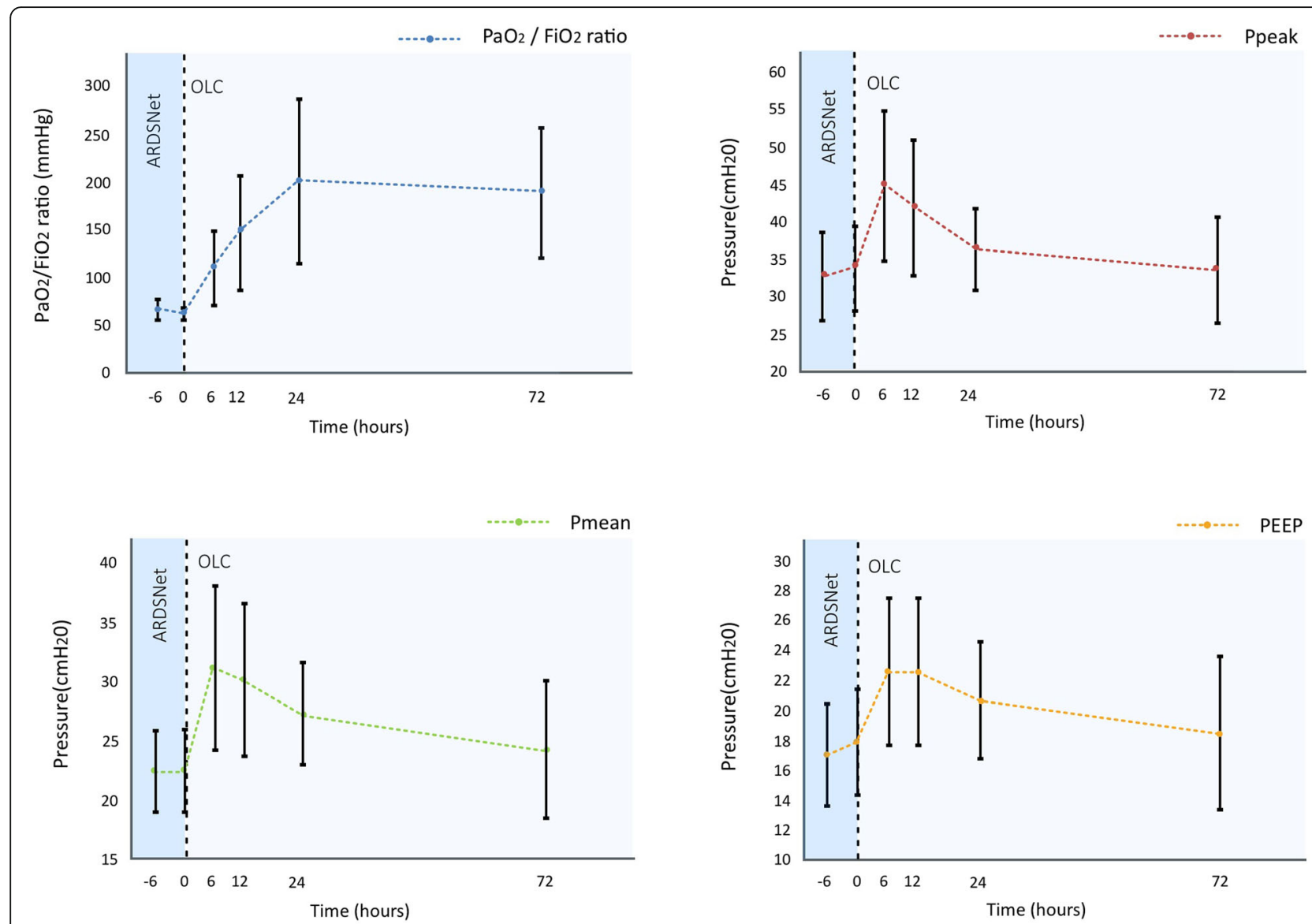

Fig. 1 Airway pressures and $\mathrm{PaO}_{2} / \mathrm{FiO}_{2}$ ratio after initiation of the OLC. Peak airway pressure, Pmean, $\mathrm{PEEP}$ and $\mathrm{PaO}_{2} / \mathrm{FiO}_{2}$ ratio as a function of time. The OLC is initiated at TO, i.e. at referral. Mean values and standard deviations are shown. Note that PEEP values are set PEEP levels at the mechanical ventilator. The depicted driving pressure is overestimated as intrinsic PEEP is not shown. $\mathrm{FiO}_{2}$ fraction of inspired oxygen, $\mathrm{PaO} 2$ partial pressure of arterial oxygen, Ppeak peak airway pressure, Pmean mean airway pressure, PEEP positive end-expiratory pressure

'recruitability' was not assessed. We hypothesize that a recruitment maneuver and higher PEEP is beneficial in patients with large regions of decreased lung aeration. Thus, future research should focus on individual 'recruitability' [6]. Baedorf Kassis et al. introduced a recruitment maneuver based on $\mathrm{P}_{\mathrm{L}}$ measurements [7]. Other potential predictors are a decrease in driving pressure, oxygenation response to PEEP-trials, or lung aeration estimated by electrical impedance tomography or ultrasound.

\section{Additional file}

Additional file 1: Figure S1. Flowchart of patient inclusion. Table S1. Patient demographics. Table S2. Patient parameters. Appendix Mechanical ventilation strategy. (DOCX $38 \mathrm{~kb}$ )

\section{Funding}

None.

\section{Availability of data and materials}

The dataset used and/or analyzed during the current study are available from the corresponding author on reasonable request.
Authors' contributions

PZ drafted the manuscript, DM, JM, HE, and DG substantially revised the manuscript. All authors approved the submitted version.

\section{Ethics approval and consent to participate}

This retrospective study was approved by the medical ethics committee of the Erasmus MC (MEC-2018-1300). According to Dutch law no informed consent was required with anonymous retrospective data.

\section{Consent for publication}

Not applicable.

\section{Competing interests}

Dinis Dos Reis Miranda received speakers fee and travel expenses from Xenios and Hill-Rom.

Diederik Gommers received speakers fee and travel expenses from Dräger, GE Healthcare (medical advisory board 2009-2012), Maquet, and Novalung (medical advisory board).

Philip van der Zee, Han Meeder, and Henrik Endeman report no competing interests.

\section{Publisher's Note}

Springer Nature remains neutral with regard to jurisdictional claims in published maps and institutional affiliations. 
Received: 13 March 2019 Accepted: 3 April 2019

\section{Published online: 23 April 2019}

\section{References}

1. Combes A, Hajage D, Capellier G, Demoule A, Lavoue S, Guervilly C, Da Silva D, Zafrani L, Tirot P, Veber B, Maury E, Levy B, Cohen Y, Richard C, Kalfon P, Bouadma L, Mehdaoui H, Beduneau G, Lebreton G, Brochard L, Ferguson ND, Fan E, Slutsky AS, Brodie D, Mercat A, Eolia Trial Group R, Ecmonet. Extracorporeal membrane oxygenation for severe acute respiratory distress syndrome. N Engl J Med. 2018;378:1965-75.

2. Gattinoni L, Vasques F, Quintel M. Use of ECMO in ARDS: does the EOLIA trial really help? Crit Care. 2018;22:171.

3. van der Zee P, Gommers D, (2019) Recruitment maneuvers and higher PEEP, the so-called open lung concept, in patients with ARDS. Crit Care 23: 73.

4. Grasso S, Terragni P, Birocco A, Urbino R, Del Sorbo L, Filippini C, Mascia L, Pesenti A, Zangrillo A, Gattinoni L, Ranieri VM. ECMO criteria for influenza a (H1N1)-associated ARDS: role of transpulmonary pressure. Intensive Care Med. 2012;38:395-403.

5. Writing Group for the Alveolar Recruitment for Acute Respiratory Distress Syndrome Trial I, Cavalcanti AB, Suzumura EA, Laranjeira LN, Paisani DM, Damiani LP, Guimaraes HP, Romano ER, Regenga MM, Taniguchi LNT, Teixeira C, Pinheiro de Oliveira R, Machado FR, Diaz-Quijano FA, Filho MSA, Maia IS, Caser EB, Filho WO, Borges MC, Martins PA, Matsui M, OspinaTascon GA, Giancursi TS, Giraldo-Ramirez ND, Vieira SRR, Assef M, Hasan MS, Szczeklik W, Rios F, Amato MBP, Berwanger O, Ribeiro de Carvalho CR. Effect of lung recruitment and titrated positive end-expiratory pressure (PEEP) vs low PEEP on mortality in patients with acute respiratory distress syndrome: a randomized clinical trial. Jama. 2017;318:1335-45.

6. Chiumello D, Brochard L, Marini JJ, Slutsky AS, Mancebo J, Ranieri VM, Thompson BT, Papazian L, Schultz MJ, Amato M, Gattinoni L, Mercat A, Pesenti A, Talmor D, Vincent JL. Respiratory support in patients with acute respiratory distress syndrome: an expert opinion. Crit Care. 2017;21:240.

7. Baedorf Kassis E, Loring SH, Talmor D. Recruitment maneuvers: using transpulmonary pressure to help goldilocks. Intensive Care Med. 2017; 43:1162-3. 